\title{
Lack of ear care knowledge in nursing homes
}

This article was published in the following Dove Press journal:

Journal of Multidisciplinary Healthcare

30 September 2016

Number of times this article has been viewed

\author{
Jorunn Solheim' \\ Olga Shiryaeva' \\ Kari J Kvaerner ${ }^{2}$ \\ 'Department of Ear, Nose and Throat, \\ Lovisenberg Diakonale Hospital, ${ }^{2} \mathrm{C} 3$ \\ Centre for Connected Care, Oslo \\ University Hospital, Oslo, Norway
}

Background: Rising life expectancy means an increase in the number of elderly people with hearing loss in the population. Many elderly people live in nursing homes, with varying care needs. A substantial proportion of these people will need help with their hearing aids and other hearing devices.

Objective: The objective of the study has been to assess the knowledge, experience, skills, competence, and need for information of staff at nursing homes in relation to residents' hearing loss and hearing aids.

Materials and methods: One hundred and ninety-five employees at seven nursing homes participated in the study. The main approach was a descriptive study, using questionnaires.

Results: The main findings are that $73 \%$ of informants found that many residents need help with their hearing aids. Only one-tenth report that they know enough about the residents' hearing aids. Almost four out of five informants find that the residents become socially isolated as a result of hearing loss. Seventy-eight percent agree to some extent that more residents would benefit from hearing aids.

Conclusion: Staff at nursing homes have insufficient knowledge about hearing loss and hearing aids. Increased focus on the elderly with hearing impairment in nursing homes is needed. Contact between nursing homes and audiological specialists should be improved to best followup hearing loss and hearing aids.

Keywords: hearing aids, nursing staff, hearing impairment, institutionalized elderly

\section{Introduction}

Hearing loss is among the most frequent chronic health problems in the elderly. ${ }^{1}$ A Norwegian survey (HUNT [Nord-Trondelag Health Study]) found that $60 \%$ of the population aged $60-79$ and $90 \%$ of people aged $\geq 80$ had acquired hearing loss. Almost half of the group experienced problems associated with this loss. ${ }^{2}$ The rise in life expectancy of populations in the Western world is leading to a considerable increase in the number of elderly people with hearing impairment. ${ }^{3}$ However, the findings show that hearing loss among the elderly is often ignored by health care workers, as other diagnoses and types of sensory loss receive more attention and higher priority. ${ }^{4-6}$

Studies have shown a significant link between hearing loss and deteriorated quality of life among the elderly. ${ }^{7-11}$ Greater incidences of loneliness, lower level of mastery, and a smaller social network have also been reported. ${ }^{12-15}$ Hearing loss among the elderly is also associated with incidence of depression. ${ }^{16-19}$ Studies have indicated that this link fully or partly attenuates after fitting hearing aids. ${ }^{20-22}$ However, the predominantly
Correspondence: Jorunn Solheim Department of ENT, Lovisenberg Diakonale Hospital, Lovisenberggata I5, 0456 Oslo, Norway

Tel +479059286I

Email jorunn.solheim@lds.no

Dovepress 1 in


technological focus on audiological rehabilitation has also been criticized. ${ }^{23}$ It has been pointed out that the incidence of depression cannot necessarily be solely attributed to the hearing loss, but that it can also be related to circumstances of a psychosocial nature, like a person's relationship with their close relatives and social networks. ${ }^{24-26}$ Additionally, there are older people who are regular hearing aid users who still experience communication difficulties and continue to report difficulties in everyday life..$^{23,27}$ The importance of addressing nonaudiological factors in order to assist older adults achieve success with hearing aids has been highlighted. ${ }^{28}$

Many elderly people are in a particularly difficult situation because they often experience hearing loss as an extra burden, in addition to generally reduced capacity and health. ${ }^{29,30}$ A considerable number of elderly people will have trouble with their hearing and vision. This is referred to as double trouble. ${ }^{31}$ A significant link has been shown between sensory loss and the need for help in relation to activities of daily living and instrumental activities of daily living, ${ }^{32-35}$ as well as a higher incidence of sensory loss among elderly people in retirement and nursing homes. ${ }^{36-38}$ Hearing loss is presumed to be among the most frequently underdiagnosed conditions in people suffering from Alzheimers. ${ }^{39}$

The presumed level of hearing aid use varies widely. Studies have shown that 3\%-25\% of hearing aids distributed are not in use. ${ }^{29,40-45}$ The ability to handle tasks that require fine motor skills deteriorates with age, and is considered to partly account for the fact that many hearing aids are not used. ${ }^{42,44}$ Problem-oriented preconceptions to hearing aids may explain the lack of hearing aid use. ${ }^{46}$ Senile dementia may also result in the forgetting of knowledge acquired in the past, and a weakening of the ability to acquire new knowledge. ${ }^{5,47}$ Background noise is found to be a key factor for the low uptake of hearing aids among people in residential care settings. ${ }^{48,49}$ Discomfort and pain attached to wearing hearing aids are also frequently mentioned reasons for nonuse. ${ }^{50,51}$ These factors may both individually and jointly have a considerable impact on the mastery of hearing aids, as well as their use and utility value. Out of Norway's population of about 5.2 million people, at present, 148,000 people receive health care at home every year (home nursing care) and 90,000 receive assisted services in their homes by health care providers. About 40,000 elderly people (aged 67 and over) are in fulltime nursing care. ${ }^{52}$ Elderly people in nursing homes often rely on care workers to help them with their hearing aids and other hearing devices. Studies have revealed that many nursing home residents have hearing aids that do not work adequately or are not in use. , $, 6,53-55^{-5}$
Table I Demographic characteristics of the study population $(n=195)$

n (\%)

\begin{tabular}{ll}
\hline Sex & \\
Females & $169(87)$ \\
Males & $26(13)$ \\
Age (years) & \\
$<20$ & $3(2)$ \\
$20-29$ & $35(20)$ \\
$30-39$ & $46(26)$ \\
$40-49$ & $39(22)$ \\
$50-59$ & $42(24)$ \\
$\geq 60$ & $11(6)$ \\
Employment (\%) & \\
I00 & $93(48)$ \\
$\approx 75$ & $68(35)$ \\
$\leq 50$ & $34(17)$ \\
Position & \\
Care assistant/unskilled/student & $36(18)$ \\
Auxiliary nurse/health care worker/activity therapist & $95(49)$ \\
Nurse/social educator/ergonomist & $61(31)$ \\
Other & $3(2)$ \\
\hline
\end{tabular}

The objective of the study was to assess the knowledge, experience, skills, competence, and need for information of staff at nursing homes in relation to the residents' hearing loss and hearing aids.

\section{Materials and methods}

\section{Participants}

The study's informants were recruited from seven nursing homes. Questionnaires were delivered to 228 employees, and 201 forms were returned (response rate $89 \%$ ). Six forms were excluded as a result of inadequate data entry. A total of 169 females and 26 males, aged 18-69, participated. The average age was 40.9 (standard deviation 12.31). The informants worked in the rehabilitation department $(5 \%)$, short-term care department (10\%), long-term care department (51\%), dementia department (22\%), and other (12\%) (Table 1).

\section{Questionnaire}

There is limited research focusing on skills, knowledge, and experiences held by employees in residential homes toward their residents' hearing loss and hearing aids. The current questionnaire was constructed based on previous research on elderly hearing impaired people in residential care settings, primarily applying the current project members' academic background and work experience. Each member of the project group had practical experience from the field, as either nurse, technical audiologist, auxiliary nurse, doctor, or educational audiologist. Subsequently other health and audiological professionals were consulted, and their opinions were taken into consideration. 
Two pilot surveys were carried out and reviewed prior to the finalization of the present questionnaire version. The questionnaire began with a presentation of the objective of the survey, and was divided into the following sections: 1) personal details; 2) knowledge and experience; 3) skills and competence; and 4) information needs. The response options were strongly agree, slightly agree, neutral, slightly disagree, and strongly disagree.

\section{Data collection}

The general managers of seven nursing homes in Oslo and Bergen (Norway) were contacted, and written and verbal information was provided about the objective of the survey, as well as information that participation was voluntary, and that the questionnaire did not contain any personal data that would allow the respondent to be identified. The survey was conducted on the same date at each institution, in order to ensure that the sample was random. All employees (no exclusion criteria) at work on the day in question were asked to complete the survey, regardless of age, sex, percentage of a full-time position, or occupational background.

The survey was exempt from the obligation to seek approval from the The Norwegian Regional Committees for Medical and Health Research Ethics because it was conducted anonymously with no identifying information. The study was performed in accordance with the Declaration of Helsinki.

\section{Statistical analysis}

All the analyses were conducted using SPSS version 22 (IBM Corp., Armonk, NY, USA). Descriptive statistics (mean \pm standard deviation) and numbers (percent) were used to summarize sample characteristics and questionnaire responses. Chi-square tests were used for group comparisons on categorical variables. All tests were two-sided. $P$-values $<0.05$ were considered to be statistically significant for all analyses.

The informants' ages were split into the following four age groups: 20-29, 30-39, 40-49, and 50-59, with informants aged $<20(n=2)$ and $\geq 60(n=6)$ being sorted into adjacent age groups. The percentage of a full-time position was classified as $\approx 75 \%$ if the informants reported $>50 \%$ and $<100 \%$. Informants with an occupational background that was classified as "Other" ( $n=3)$ were excluded from the analysis. In descriptive analyses, statements about the staff's knowledge, experience, and need for information were dichotomized as agreement (strongly agree or slightly agree) or disagreement (neutral, slightly disagree, or strongly disagree).

\section{Results}

A total of 195 informants participated in the project. The average informant was a female aged 40 , with lower-level health education, who worked full-time at a long-term care department at a nursing home. The following results all refer to Figure 1, based on the questionnaire options strongly agree and slightly agree. A complete overview of the results can be found in Table S1.

\section{Knowledge and experience}

While only $23 \%$ of the informants stated that they had received training in the use and care of hearing aids, $83 \%$ agreed that many residents need help with their hearing aids. Twenty-nine percent believed they had adequate knowledge about the residents' hearing aids, and 78\% reported that the residents became socially isolated because of hearing loss. Seventy-eight percent agreed that more residents would probably benefit from hearing aids.

\section{Skills and competence}

While $64 \%$ of the informants regularly checked the battery's + side before inserting it into the hearing aid, only $29 \%$ were familiar with the approximate lifetime of a hearing aid battery. The informants considered themselves able to provide hearing aid assistance to varying degrees; $35 \%$ were unable to provide the necessary assistance. Half of the informants believed that hearing aids were not in use because residents do not master their use. Almost one-third were of the impression that residents were satisfied with their hearing aids. When asked whether hearing aid users were checked regularly for earwax, 34\% agreed. Additionally, earwax was not cleared from earmolds regularly; only $30 \%$ stated that this was done routinely.

\section{Need for information}

Eighty percent stated that they needed information about hearing loss among the elderly, and $88 \%$ were in need of more information about different types of hearing aids.

\section{Age, employment, and occupational background}

The oldest group of informants (aged $\geq 50$ ) reported more knowledge on hearing aid batteries $(P=0.004)$, more frequently noted whistling of the residents' hearing aids $(P=0.01)$, and stated that the residents did not master the use of hearing aids $(P=0.03)$. They also had the higher score on requested need for knowledge about different hearing aid models $(P=0.006)$. On average, the age group 20-29 had the lowest score. The percentage of a full-time position held by the individual informants did not reflect significant 


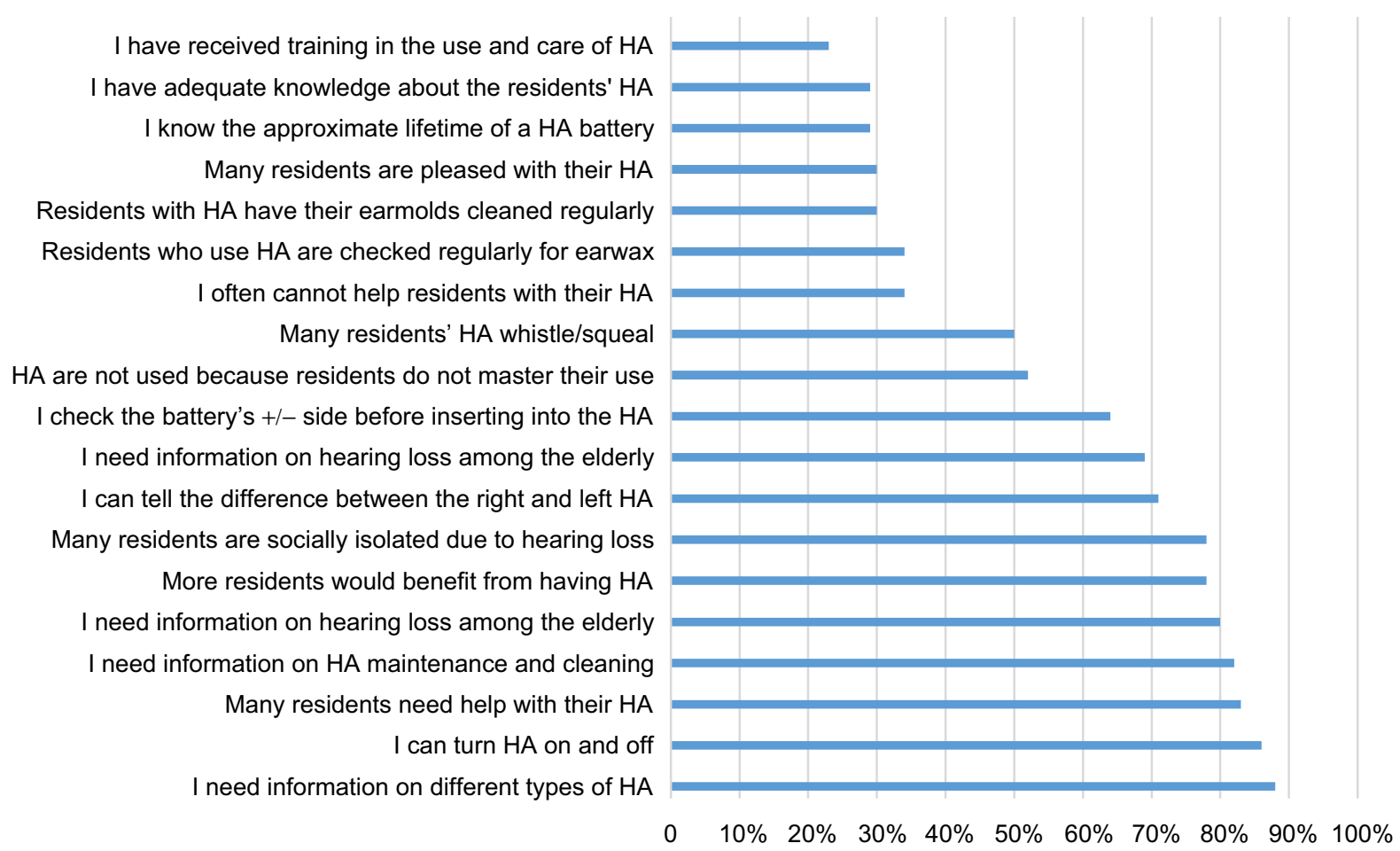

Figure I Agreement on knowledge, experiences, skills, and expressed need for information on hearing loss and HA use ( $n=192)$. Abbreviation: HA, hearing aid.

differences between those who worked full-time and those who had part-time positions.

Overall, the group of activity therapists, health care workers, auxiliary nurses, and assistant occupational therapists believed that they had adequate information about the residents' hearing aids $(P=0.002)$. They reported more often that hearing aids whistled $(P=0.03)$, and took the initiative more frequently to replace the tubes on hearing aids $(P=0.03)$ than other occupational groups. The group of nurses/social educators/occupational therapists reviewed the residents' need for assistance with the use of hearing aids more frequently than other occupational groups $(P=0.02)$.

\section{Discussion}

Our results show that nursing home staff report insufficient knowledge, information, and practical skills regarding elderly residents' hearing aids.

\section{Knowledge and experiences}

Our study found that a minority of staff at nursing homes have received training on the use and care of hearing aids, and that a correspondingly low proportion believes that they have enough knowledge about the residents' hearing aids. This represents a challenge for hearing aid users at nursing homes dependent on assisted care. However, care workers cannot be expected to have comprehensive knowledge on hearing aids and other hearing devices. There is a large selection of hearing aids on the market, different manufacturers, models, specifications, and functions. At the same time, new models keep being launched. This calls for a closer collaboration between audiological professionals and health care workers. As the latter represents the connecting link to the hearing aid user, they should be provided with sufficient knowledge to contact audiological professionals for follow-up support when problems arise. However, some basic knowledge about the use and maintenance of hearing aids is needed - both to provide simple "first aid" and to perform necessary maintenance. For example, problems associated with earwax are frequently reported causes of reduced auditory function and lack of hearing aids use among the elderly in nursing homes. ${ }^{6.56}$ The need for care workers to have some basic knowledge about the use and care of hearing aids is reflected in a large share of the informants believing that the residents need help with their hearing aids.

Considering the current knowledge on the relationship between hearing loss and health-related quality of life, ${ }^{12-14}$ 
it is worrying that the informants report that social isolation may be due to hearing loss. A great majority believe that their residents would benefit from a hearing aid. Communication and social interaction are important throughout a person's life. Functional hearing provides a sense of safety and predictability, and allows for conversation and social interaction. ${ }^{57}$ Additionally, functional hearing may be critical to navigate in a society in which the ability to hear is essential. ${ }^{58}$ The ability to hear also serves an important function in cognitive stimulation and is of great importance to mental health. ${ }^{57}$

\section{Skills and competence}

The uncertainty associated with telling the difference between the right and the left hearing aid suggests that some residents' hearing aids are placed in the wrong ear, which can have implications for hearing. These include: physical discomfort, risk of pressure sores, a programming profile that is not adapted to the specific type of hearing loss, earmolds that do not fit the ear canal, feedback problems ("squealing"), and increase in the probability of the hearing aid dropping out of the user's ear - all resulting in discomfort and frustration.

As very few employees at nursing homes check the battery's +/- side before they insert it into the hearing aid, this can result in batteries being inserted incorrectly. In practice, this means that the hearing aid shuts out sound instead of allowing sound in. There is also little knowledge about the lifetime of hearing aid batteries. After the battery has worn out, the hearing aid will literally act as a protection against hearing.

Inadequate knowledge and practical skills among care workers may have major consequences for the elderly hearing aid users who are dependent on care. Many users experience hearing aid whistling; a nuisance to themselves, other residents, and the staff at the institution. The feedback problem is often due to earwax, but it may also be that hearing aids are inserted into the wrong ear. One out of three informants ensures that residents' ears are regularly checked for earwax and that earmolds are cleaned. This indicates a lack of regular cleaning procedures. It is important that earwax is removed regularly in order to optimize the transfer of sound from the hearing aid to the ear. In the worst case, the sound outlet of the earmolds will be clogged with earwax, and in practice obstructs hearing. Consequently, a person's ability to hear will deteriorate.

Hearing aids may not be used due to insufficient mastery among the residents. The majority of health care workers do not find themselves competent to provide necessary help. This may reduce the elderly's opportunities for necessary contact with other people. Only one-third believe that the residents are satisfied with their hearing aids. This provides an indication that elderly hearing aid users should receive greater follow-up than is the current practice. On the other hand, hearing aids should not be regarded as the panacea for all elderly who are hearing impaired, as other hearing devices may be more useful to some. The elderly do not necessarily consider themselves to be hearing impaired, and reject using their aids. ${ }^{46,59,60}$ Supplemental and alternative forms of interventions should be considered to ensure individual needs as well as autonomy.

\section{Need for information}

Overall, informants report a high need for general information about hearing loss and hearing aids; the staff want to meet the residents' hearing needs. When health care workers express a great need for information about hearing loss regardless of their occupational background, sex, age, and percentage of a full-time position, this needs to be addressed. In practice, they handle their residents' care, provide practical assistance, and the best possible quality of life. As previously emphasized, closer collaboration between audiological professionals and health workers is needed, ie, by establishing regular follow-up-instruction series in nursing homes, or offering a personalized hearing aid handbook with essential hearing aid information (brand/model, serial number, batteries, date/year of hearing aid assignment, information on audiological professionals etc) to the hearing aid user. The latter is routinely offered to all hearing aid users referred to Lovisenberg Diakonale Hospital, an Oslo community hospital. ${ }^{61}$

\section{Results by age, employment, and occupational background}

The oldest group of informants (aged $\geq 50$ ) appears to focus the most on the residents' hearing aids. This is hardly surprising, considering they have most working experience. The same group also wanted more knowledge about different types of hearing aids. This group often has acquired practical skills that enable them to support the elderly in handling their hearing aids. It is important that the knowledge and experience held by the oldest and most experienced staff are transferred to younger staff. However, there is still a risk that the above-mentioned knowledge may become outdated as hearing aid technology progresses. ${ }^{62,63}$ This makes contact with audiological specialists even more 
important in order for people to update their knowledge and competence.

\section{Study limitations}

Despite a high response rate (89\%), our study may have some limitations. Lack of a validated questionnaire appropriate for our target group of nursing home employees made it necessary to design a questionnaire covering essential aspects of the subject targeted. After the completion of two pilots with subsequent review, we found the questionnaire appropriate for our study. It needs to be validated for the use in other settings. Subjective assumptions and preconceptions may have influenced the preparation of the questionnaire in the direction of sidedness and a less well-balanced questionnaire. Therefore, we anticipate further research focusing on the elderly hearing impaired in residential homes, and their need for follow-up support.

\section{Conclusion}

Hearing loss primarily represents a communication handicap that may affect individuals' opportunities to interact with their surroundings. Our findings show that there is a need for more knowledge about hearing loss and better follow-up of hearing aid users in nursing homes, in order to improve their auditory function and ability to communicate. The number of elderly people will increase in the years ahead, as will the need for audiological rehabilitation. Many elderly people will be dependent on practical help with hearing aids and other hearing devices.

Audiological rehabilitation is of great importance in order to prevent problems and improve the quality of life of the elderly. Contact between nursing homes and audiological specialists must be improved to address health care workers' need for knowledge. It is obvious that elderly hearing aid users should be checked regularly, and the need for earwax removal is addressed. Regular checking of hearing aids is required to ensure that the devices are functioning properly and are being used correctly.

\section{Acknowledgments}

This project has been made possible by the Norwegian ExtraFoundation for Health and Rehabilitation. We would also like to thank the Norwegian Association of the Hearing Impaired, and Lovisenberg Diakonale Hospital for practical and financial support.

\section{Disclosure}

The authors report no conflicts of interest in this work.

\section{References}

1. Davis A, Davis K. Epidemiology of aging and hearing loss related to other chronic illnesses. Hear Care Adults. 2009;23-32.

2. Tambs K. Utbredelse av hørselstap [Prevalence of hearing impairment]. Nytt fra Miljø og Samfunnsmedisin. 1998;20:1. Norwegian.

3. Sorri M, Roine R. Age-adjusted prevalence of hearing impairment has significantly increased during the last two decades. Scand Audiol Suppl. 2001;(54):5-7.

4. Meyer C, Hickson L. What factors influence help-seeking for hearing impairment and hearing aid adoption in older adults? Int $J$ Audiol. 2012;51(2):66-74.

5. Wallhagen MI, Pettengill E. Hearing impairment: significant but underassessed in primary care settings. J Gerontol Nurs. 2008;34(2):36-42.

6. Yueh B, Shapiro N, MacLean CH, Shekelle PG. Screening and management of adult hearing loss in primary care: scientific review. JAMA. 2003;289(15):1976-1985.

7. Dalton DS, Cruickshanks KJ, Klein BE, Klein R, Wiley TL, Nondahl DM. The impact of hearing loss on quality of life in older adults. Gerontologist. 2003;43(5):661-668.

8. Gopinath B, Schneider J, Hickson L, McMahon CM, Burlutsky G, Leeder SR, Mitchell P. Hearing handicap, rather than measured hearing impairment, predicts poorer quality of life over 10 years in older adults. Maturitas. 2012;72(2):146-151.

9. Joore MA, Brunenberg DE, Chenault MN, Anteunis LJ. Societal effects of hearing aid fitting among the moderately hearing impaired. Int J Audiol. 2003;42(3):152-160.

10. Lopez D, McCaul KA, Hankey GJ, et al. Falls, injuries from falls, health related quality of life and mortality in older adults with vision and hearing impairment - is there a gender difference? Maturitas. 2011;69(4):359-364.

11. Strawbridge WJ, Wallhagen MI, Shema SJ, Kaplan GA. Negative consequences of hearing impairment in old age: a longitudinal analysis. Gerontologist. 2000;40(3):320-326.

12. Kramer SE, Kapteyn TS, Kuik DJ, Deeg DJ. The association of hearing impairment and chronic diseases with psychosocial health status in older age. J Aging Health. 2002;14(1):122-137.

13. Pronk M, Deeg DJ, Smits C, van Tilburg TG, Kuik DJ, Festen JM, Kramer SE. Prospective effects of hearing status on loneliness and depression in older persons: identification of subgroups. Int J Audiol. 2011; 50(12):887-896.

14. Mick P, Kawachi I, Lin FR. The association between hearing loss and social isolation in older adults. Otolaryngol Head Neck Surg. 2014;150(3):378-384.

15. Haanes GG, Kirkevold M, Hofoss D, Horgen G, Eilertsen G. An intervention designed to improve sensory impairments in the elderly and indoor lighting in their homes: an exploratory randomized controlled trial. J Multidiscip Healthc. 2015;8:11-20.

16. Gopinath B, Schneider J, McMahon CM, Teber E, Leeder SR, Mitchell P. Severity of age-related hearing loss is associated with impaired activities of daily living. Age Ageing. 2012;41(2):195-200.

17. Ishine M, Okumiya K, Matsubayashi K. A close association between hearing impairment and activities of daily living, depression, and quality of life in community-dwelling older people in Japan. J Am Geriatr Soc. 2007;55(2):316-317.

18. Lee AT, Tong MC, Yuen KC, Tang PS, Vanhasselt CA. Hearing impairment and depressive symptoms in an older Chinese population. J Otolaryngol Head Neck Surg. 2010;39(5):498-503.

19. Mohlman J. Cognitive self-consciousness - a predictor of increased anxiety following first-time diagnosis of age-related hearing loss. Aging Ment Health. 2009;13(2):246-254.

20. Acar B, Yurekli MF, Babademez MA, Karabulut H, Karasen RM. Effects of hearing aids on cognitive functions and depressive signs in elderly people. Arch Gerontol Geriatr. 2011;52(3):250-252.

21. Boi R, Racca L, Cavallero A, et al. Hearing loss and depressive symptoms in elderly patients. Geriatr Gerontol Int. 2012;12(3):440-445.

22. Mulrow CD, Aguilar C, Endicott JE, et al. Quality-of-life changes and hearing impairment. A randomized trial. Ann Intern Med. 1990;113(3): 188-194. 
23. Hickson L, Worrall L. Beyond hearing aid fitting: improving communication for older adults. Int J Audiol. 2003;42(Suppl 2):2S84-2S91.

24. Chew HS, Yeak S. Quality of life in patients with untreated age-related hearing loss. J Laryngol Otol. 2010;124(8):835-841.

25. Chou KL, Chi I. Combined effect of vision and hearing impairment on depression in elderly Chinese. Int J Geriatr Psychiatry. 2004;19(9): $825-832$.

26. Tambs K. Moderate effects of hearing loss on mental health and subjective well-being: results from the Nord-Trondelag Hearing Loss Study. Psychosom Med. 2004;66(5):776-782.

27. Dawes P, Maslin M, Munro KJ. 'Getting used to' hearing aids from the perspective of adult hearing-aid users. Int J Audiol. 2014;53(12): 861-870.

28. Hickson L, Meyer C, Lovelock K, Lampert M, Khan A. Factors associated with success with hearing aids in older adults. Int J Audiol. 2014;53 Suppl 1:S18-S27.

29. Lupsakko TA, Kautiainen HJ, Sulkava R. The non-use of hearing aids in people aged 75 years and over in the city of Kuopio in Finland. Eur Arch Otorhinolaryngol. 2005;262(3):165-169.

30. Grue EV, Kirkevold M, Mowinchel P, Ranhoff AH. Sensory impairment in hip-fracture patients 65 years or older and effects of hearing/ vision interventions on fall frequency. J Multidiscip Healthc. 2008;2: $1-11$.

31. Berry P, Mascia J, Steinman BA. Vision and hearing loss in older adults: "Double trouble". Care Manag J. 2004;5(1):35-40.

32. Grue EV, Ranhoff AH, Noro A, et al. Vision and hearing impairments and their associations with falling and loss of instrumental activities in daily living in acute hospitalized older persons in five Nordic hospitals Scand J Caring Sci. 2009;23(4):635-643.

33. Yamada M, Nishiwaki Y, Michikawa T, Takebayashi T. Impact of hearing difficulty on dependence in activities of daily living (ADL) and mortality: a 3-year cohort study of community-dwelling Japanese older adults. Arch Gerontol Geriatr. 2011;52(3):245-249.

34. Haanes GG, Kirkevold M, Horgen G, Hofoss D, Eilertsen G. Sensory impairments in community health care: a descriptive study of hearing and vision among elderly Norwegians living at home. J Multidiscip Healthc. 2014;7:217-225.

35. Eklund K, Dahlin-Ivanoff S. Low vision, ADL and hearing assistive device use among older persons with visual impairments. Disabil Rehabil Assist Technol. 2007;2(6):326-334.

36. Cohen-Mansfield J, Taylor JW. Hearing aid use in nursing homes. Part 1: prevalence rates of hearing impairment and hearing aid use. $J \mathrm{Am}$ Med Dir Assoc. 2004;5(5):283-288.

37. van der Pols JC, Bates CJ, McGraw PV, Thompson JR, Reacher M, Prentice A, Finch S. Visual acuity measurements in a national sample of British elderly people. Br J Ophthalmol. 2000;84(2):165-170.

38. Owsley C, McGwin G, Scilley K, Meek GC, Dyer A, Seker D. The visual status of older persons residing in nursing homes. Arch Ophthalmol. 2007;125(7):925-230.

39. Bakhos D, Villeuneuve A, Kim S, Hammoudi K, Hommet C. Hearing loss and Alzheimer's disease. Geriatr Psychol Neuropsychiatr Vieil. 2015; 13(2):195-204.

40. Chia EM, Mitchell P, Rochtchina E, Foran S, Golding M, Wang JJ. Association between vision and hearing impairments and their combined effects on quality of life. Arch Ophthalmol. 2006;124(10):1465-1470.

41. Parving A, Philip B. Use and benefit of hearing aids in the tenth decade - and beyond. Audiology. 1991;30(2):61-69.
42. Gimsing S. [Use of hearing aids five years after issue]. Ugeskr Laeger. 2008;170(43):3407-3411. Danish.

43. Smeeth L, Fletcher AE, Ng ES, et al. Reduced hearing, ownership, and use of hearing aids in elderly people in the UK - the MRC Trial of the Assessment and Management of Older People in the Community: a cross-sectional survey. Lancet. 2002;359(9316):1466-1470.

44. Vuorialho A, Sorri M, Nuojua I, Muhli A. Changes in hearing aid use over the past 20 years. Eur Arch Otorhinolaryngol. 2006;263(4):355-360.

45. Solheim J, Kvaerner KJ, Sandvik L, Falkenberg E-S. Factors affecting older adults' hearing-aid use. Scand J Disabil Res. 2012;14(4):300-312.

46. Solheim J. Preconceptions and expectations of older adults about getting hearing aids. J Multidiscip Healthc. 2011;4:1-8.

47. Kravitz E, Schmeidler J, Beeri MS. Cognitive decline and dementia in the oldest-old. Rambam Maimonides Med J. 2012;3(4):e0026.

48. Tolson D. Age-related hearing loss: a case for nursing intervention. $J$ Adv Nurs. 1997;26(6):1150-1157.

49. Pryce H, Gooberman-Hill R. 'There's a hell of a noise': living with a hearing loss in residential care. Age Ageing. 2012;41(1):40-46.

50. McCormack A, Fortnum H. Why do people fitted with hearing aids not wear them? Int J Audiol. 2013;52(5):360-368.

51. Liston R, Solomon S, Banerjee AK. Prevalence of hearing problems, and use of hearing aids among a sample of elderly patients. $\mathrm{Br} \mathrm{J} \mathrm{Gen}$ Pract. 1995;45(396):369-370.

52. Statistics Norway. Nursing and care services, 2015. Available from: www.ssb.no/en/helse/statistikker/pleie. Accessed August 26, 2016.

53. Keller BK, Morton JL, Thomas VS, Potter JF. The effect of visual and hearing impairments on functional status. J Am Geriatr Soc. 1999; 47(11):1319-1325.

54. Stumer J, Hickson L, Worrall L. Hearing impairment, disability and handicap in elderly people living in residential care and in the community. Disabil Rehabil. 1996;18(2):76-82.

55. Tsuruoka H, Masuda S, Ukai K, Sakakura Y, Harada T, Majima Y. Hearing impairment and quality of life for the elderly in nursing homes. Auris Nasus Larynx. 2001;28(1):45-54.

56. Lim JK, Yap KB. Screening for hearing impairment in hospitalised elderly. Ann Acad Med Singapore. 2000;29(2):237-241.

57. Palmer AD, Newsom JT, Rook KS. How does difficulty communicating affect the social relationships of older adults? An exploration using data from a national survey. J Commun Disord. 2016;62:131-146.

58. Lopez-Torres HidalgoJ, Boix Gras C, Tellez Lapeira J, Lopez Verdejo MA, del Campo del Campo JM, Escobar Rabadan F. Functional status of elderly people with hearing loss. Arch Gerontol Geriatr. 2009;49(1):88-92.

59. Gussekloo J, de Bont LE, von FM, et al. Auditory rehabilitation of older people from the general population - the Leiden 85-plus study. $\mathrm{Br} J$ Gen Pract. 2003;53(492):536-540.

60. Chang NC, Dai CY, Lin WY, Chien CY, Hsieh MH, Ho KY. Perception of hearing impairment and the willingness to use hearing aids in an elderly population in southern Taiwan: a community-based study. Int J Audiol. 2016;55(9):491-498.

61. Solheim J. Listen! A Handbook for Hearing Aid Users; 2016. Available from: https:/www.hlf.no/globalassets/prosjekter/prosjektdokumenter/ hor-her-boken.pdf. Accessed August 26, 2016. Norwegian.

62. Cox RM, Johnson JA, Xu J. Impact of hearing aid technology on outcomes in daily life I: the patients' perspective. Ear Hear. 2016;37(4):e224-e237.

63. Paglialonga A, Tognola G, Pinciroli F. Apps for hearing science and care. Am J Audiol. 2015;24(3):293-298. 


\section{Supplementary material}

Table SI Knowledge, skills and information needs on residents hearing loss and hearing aids

\begin{tabular}{|c|c|c|c|c|c|}
\hline Statements & $\begin{array}{l}\text { Strongly } \\
\text { agree }\end{array}$ & $\begin{array}{l}\text { Slightly } \\
\text { agree }\end{array}$ & Neutral & $\begin{array}{l}\text { Slightly } \\
\text { disagree }\end{array}$ & $\begin{array}{l}\text { Strongly } \\
\text { disagree }\end{array}$ \\
\hline \multicolumn{6}{|l|}{ Knowledge and experience } \\
\hline I have received training in the use and care of hearing aids & 11 & 12 & 26 & 15 & 36 \\
\hline Many residents need help with their hearing aids & 73 & 10 & 9 & 5 & 3 \\
\hline I have adequate knowledge about the residents' hearing aids & 10 & 19 & 29 & 25 & 17 \\
\hline It is my experience that residents are socially isolated due to hearing loss & 57 & 21 & 14 & 3 & 5 \\
\hline I emphasize lighting and sound conditions when talking to residents & 33 & 36 & 25 & 4 & 2 \\
\hline More residents would benefit from having hearing aids & 49 & 29 & 16 & 3 & 3 \\
\hline \multicolumn{6}{|l|}{ Skills and competence } \\
\hline I can turn hearing aids on and off & 77 & 9 & 5 & 2 & 7 \\
\hline I can tell the difference between the right and the left hearing aid & 57 & 14 & 16 & 5 & 8 \\
\hline I always check the battery's +/- side before inserting it into the hearing aid & 51 & 13 & 18 & 7 & 11 \\
\hline I know the approximate life of a hearing aid battery & 14 & 15 & 17 & 20 & 34 \\
\hline Many residents' hearings aids whistle/squeal & 30 & 20 & 27 & 14 & 9 \\
\hline I often cannot help residents with their hearing aids & 10 & 25 & 28 & 19 & 18 \\
\hline I take steps to make sure that residents receive (new) hearing aids & 21 & 20 & 32 & 12 & 15 \\
\hline I change the tubes in the hearing aids & 12 & 10 & 22 & 21 & 35 \\
\hline Hearing aids are not used because residents do not master their use & 25 & 27 & 23 & 11 & 14 \\
\hline It is my impression that residents are pleased with their hearing aids & 13 & 17 & 57 & 9 & 4 \\
\hline Residents who use hearing aids are checked regularly for earwax & 15 & 19 & 32 & 16 & 18 \\
\hline Residents who use hearing aids have their earmolds cleaned regularly & 13 & 17 & 36 & 24 & 10 \\
\hline Sometimes the earmolds do not fit the ear & 12 & 26 & 35 & 16 & 11 \\
\hline \multicolumn{6}{|l|}{ Information needs } \\
\hline Hearing loss among the elderly & 43 & 37 & 12 & 7 & I \\
\hline Different types of hearing aid & 63 & 25 & 7 & 5 & 0 \\
\hline Hearing aid maintenance and cleaning & 49 & 32 & 9 & 7 & 3 \\
\hline Hearing technology (hearing loops, etc) & 44 & 32 & 13 & 8 & 3 \\
\hline Contact person for residents' hearing aids & 35 & 33 & 23 & 6 & 3 \\
\hline Contact person for residents' hearing devices & 37 & 32 & 20 & 8 & 3 \\
\hline Legislation on hearing aids, hearing devices, etc & 50 & 27 & 14 & 5 & 4 \\
\hline $\begin{array}{l}\text { Hearing tactics (good lighting and sound conditions, conversation } \\
\text { techniques) }\end{array}$ & 51 & 32 & 9 & 6 & 2 \\
\hline
\end{tabular}

Notes: $n=192$. Data shown as \%.

Journal of Multidisciplinary Healthcare

\section{Publish your work in this journal}

The Journal of Multidisciplinary Healthcare is an international, peerreviewed open-access journal that aims to represent and publish research in healthcare areas delivered by practitioners of different disciplines. This includes studies and reviews conducted by multidisciplinary teams as well as research which evaluates the results or conduct of such teams or health

\section{Dovepress}

care processes in general. The journal covers a very wide range of areas and welcomes submissions from practitioners at all levels, from all over the world. The manuscript management system is completely online and includes a very quick and fair peer-review system. Visit http://www.dovepress.com/ testimonials.php to read real quotes from published authors. 